\title{
Historia de con tanto como posible marcador del discurso ${ }^{1}$
}

\author{
Por Marta Fernández Alcaide
}

\section{Conceptos}

Antes de empezar el desarrollo de este estudio, me parece fundamental definir algunos conceptos básicos que serán aquí empleados. El primero, cómo no, debe ser el de marcador del discurso, dado que lo que se discutirá aquí es si el elemento con tanto en su corta existencia puede ser considerado uno de ellos. Entiendo por marcador del discurso - y evidentemente se podrá discutir esta definición, pues la bibliografía está llena de definiciones enfrentadas ${ }^{2}$ - un recurso de cohesión textual, concretamente las partículas o locuciones que pueden introducirse para organizar los enunciados o las partes del texto, de manera que pueden conectarlos entre sí y añadir, por tanto, un significado a la relación que establecen, o simplemente caracterizarlos desde algún punto de vista.

El segundo concepto que será empleado es el de un tipo concreto de marcador del discurso denominado ordenadores de la materia discursiva, que interesa en relación con el sintagma estudiado, pues de ser marcador del discurso podría incluirse en este grupo. Para ello se hace obligado hablar mínimamente de la clasificación de los marcadores. Pocos autores se han atrevido a ofrecer una clasificación general de los marcadores del discurso del español. La más completa y la que más suele utilizarse es la de Martín Zorraquino y Portolés Lázaro (1999). Dado que no es el objetivo de este trabajo una profundización teórica de la cuestión, he seguido y adoptado la clasificación citada, sin considerar las posibles objeciones:

1 Una primera versión de este trabajo se presentó en la Universidad de Sevilla en noviembre de 2007, como ponencia en el marco del „Coloquio Internacional in memoriam Manuel Alvar. Variación lingüística y lenguas en contacto“, recogido en Fernández Alcaide (en prensa). Otra más avanzada se presentó en Múnich, en el Coloquio de Lingüística del Institut für Romanische Philologie de la Ludwig-Maximilians-Universität, donde los colegas romanistas hicieron preguntas y comentarios que he intentado contemplar para esta publicación. A ellos dirijo mis agradecimientos.

2 Véanse, por ejemplo, Briz 2000, Casalmiglia Blancafort / Tusón Valls 1999[2002], Cano Aguilar 2003 b, Fuentes Rodríguez 1987, 1993 y 1998, García Izquierdo 1997, Martín Zorraquino / Portolés Lázaro 1999, Pons Bordería 1998, Pons Rodríguez (2009), Portolés 2001 y 2004. Cf. López Serena / Borreguero Zuloaga 2009. 


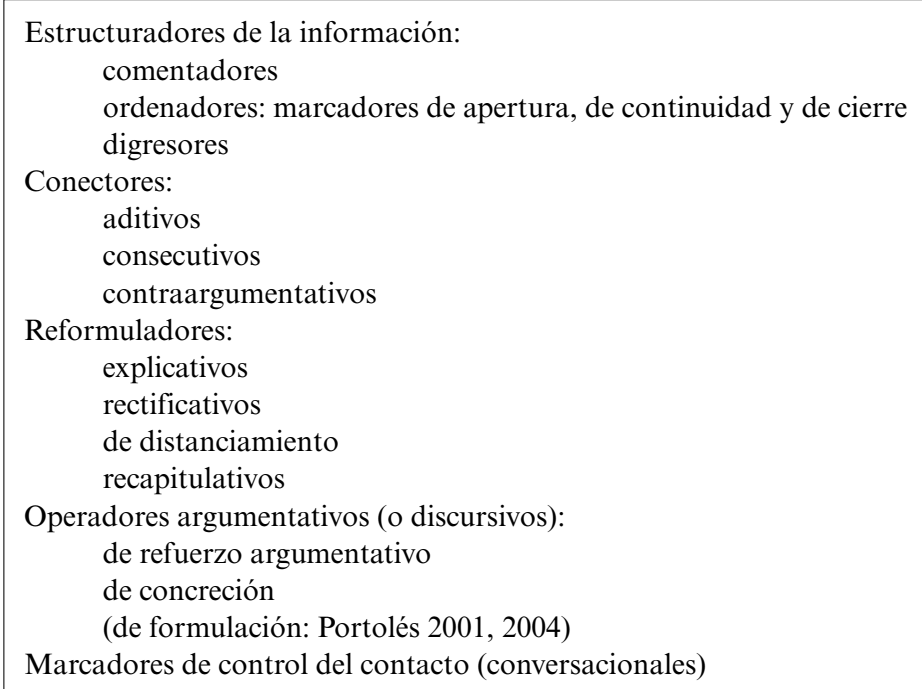

Figura 1.

Los ordenadores de la materia discursiva, dentro de los estructuradores de la información, son elementos que sirven para aludir a la estructura formal del texto. Pueden establecer un orden („ordenadores“ propiamente dichos) o una enumeración (,enumerativos“: en primer lugar / en segundo lugar, por otra parte, etc.). En uno y otro caso pueden aparecer o no los denominados „,conclusivos“, que cierren esas secuencias: finalmente, en resumen, etc., aunque ellos son independientes de los anteriores pues no requieren la presencia de ningún otro. La función principal de los conclusivos es indicar que el enunciado o la secuencia que introducen son las últimas, si bien pueden añadir alguna otra información como ocurre con en resumen, en suma, que indican final y conclusión, en una palabra, total, que aportan un valor explicativo, o sobre todo, que añade un significado argumentativo: el último elemento introducido es más relevante para la argumentación que los anteriores ( $c f$. Fuentes Rodríguez 1987, 1993; Martín Zorraquino / Portolés Lázaro 1999).

El tercer concepto al que recurriré es el de gramaticalización, dado que estará en la base de la discusión acerca de si una secuencia léxica pasa o no a formar parte de un grupo de unidades discursivas. Lo definiré más brevemente, aunque también tiene sus puntos de inflexión o conflicto. Gramaticalización es el proceso dinámico por el cual un elemento de la lengua con significado léxico se fija y pasa a formar parte, con mayor o menor estabilidad, de alguno de los grupos con significado categorial o significado instrumental ${ }^{3}$. Junto a este término, encontramos

3 Este sentido dinámico no es compartido por todos los teóricos de la gramaticalización. Lo encontramos, por ejemplo, en Company 2003, 2004a y 2004b. Cf. Detges 1998, 2000, Himmelmann 2002, etc. 
en la actualidad otro más reciente y menos extendido, que también voy a citar y definir: pragmaticalización ${ }^{4}$. Podríamos tratarlo en los mismos términos que el anterior con la diferencia de que la fijación se produce dentro de la pragmática y no de la gramática. Lo menciono porque aparece en la bibliografía, especialmente en la que se refiere a cuestiones de marcadores del discurso y el estudio del texto en general; no obstante, habría que preguntarse si esta distinción resulta pertinente en el sentido de si se cree en la pragmática como nivel lingüístico aparte de la gramática o no. Dado que soy partidaria de pensar que la pragmática, más bien, es una dimensión lingüística que atraviesa todos los niveles, me limitaré a hablar de gramaticalización cuando lo requiera.

\section{Objetivos y límites del trabajo}

De todos los elementos que desempeñan la función de ordenador de la materia discursiva me he interesado particularmente por uno que ha estado presente desde los orígenes del español, obviamente no gramaticalizado desde el principio y nunca completamente, pero que fue desterrado al concluir los Siglos de Oro. Me refiero a con tanto.

Esta era una de las posibles fórmulas con que se cerraban las cartas privadas en el siglo XVI. La detecté en la investigación desarrollada para mi tesis doctoral, basada en un corpus de 640 cartas de particulares, recogidas en el Archivo General de Indias porque se utilizaban como testimonios para pedir la licencia del pasaje a Indias (Fernández Alcaide 2009; $c f$. Otte 1988). Estas cartas fueron escritas por individuos de todas las clases sociales, de modo que el hallazgo de este marcador en las cartas muestra que formaba parte de la práctica particular en general, pues, además, se recomienda su empleo en las artes epistolares ( $c f$., por ejemplo, Torquemada 1552). Con él se marcaba el final del texto, ya que daba paso a los últimos elementos: la despedida y la datación tópica y cronológica. Las cincuenta cartas $(1,4,19,28,35,60,62,68,99,141,143,152,154,169,171,192,193,209$, $217,245,260,291,300,301,302,304,306,307,309,348,358,359,360,363,420$, $422,454,481,485,496,500,501,503,505,551,571,581,585,594,606)$ donde aparece (un $8 \%$ tan sólo del total) no comparten muchos rasgos a partir de los cuales se puedan deducir cuestiones variacionales: los emisores o remitentes comparten escribir cartas particulares desde América pero no hay homogeneidad en sus profesiones, pues lo emplean albañiles, carpinteros, curtidores, ganaderos, mercaderes, ,mineros ${ }^{6}$, clérigos e incluso abogados o, también, en más de un caso, el pendolista al que se hubiera contratado para escribir; tampoco tienen en común el tipo de relación con el destinatario, pues están dirigidas a esposas, a hermanos o hermanas, a madres, padres, hijos, sobrinos, cartas a un „señor“, a un „muy

4 Es el término que encontramos empleado, sobre todo, en trabajos de cortesía: Martínez Camino 2006, Watts 2003, etc., pero también en algunos de gramaticalización: véase, por ejemplo, el ya citado trabajo de Company 2004 a. 
magnífico señor“, a un „ilustre señor“, a un „muy reverendo señor“, a un yerno, a un cuñado, a la suegra o, simplemente, a una conocida; la variedad diatópica tampoco aporta nada relevante porque proceden de y van a lugares variados. Por tanto, en el primer acercamiento a este elemento sólo nos hacemos una idea vaga de su caracterización.

Por otra parte, con tanto seguido de la conjunción que, se utilizaba como conector interoracional, concretamente para introducir condicionales de sentido restrictivo, equivalente a ,con tal de que ${ }^{6}$, siempre y cuando que'. No obstante, en ocasiones, puede resultar difícil diferenciar ambas formas, en especial cuando se trata de traslaciones al escrito de un acto de comunicación oral:

(1) El dicho Lope de Pagamuno, capero, vesino de la dicha villa, preguntado por el dicho alcalde en el dicho caso, por el juramento que fiso dixo que en el dicho día vierrnes de mannana del dicho mes que vido de cómmo Johan Lopes de Lascano le demandó a este mesmo testigo que le diese un destral para quebrantar el postigo de la puerta de la dicha villa, e que non ge lo quiso dar. Et con tanto que fue el dicho Johan Lopes cabo la puerta de la dicha villa, e alguno que estava de partes de fuera de la dica villa que dava golpes al dicho postigo. E el dicho Johan Lopes de partes de dentro que le desía al que dava los dichos golpes que firiese resio a la dicha puerta.

1448, Anónimo, Testimonio de denuncia de sucesos [Colección diplomática del Concejo de Segura (Guipúzcoa)]. Apud CORDE.

(2) Yten, los del dicho conçejo, acatando la hedad del dicho Pero Ochoa e la fatyga y gran danno que ha resçebido despues que anda desterrado fuera de la dicha villa, les plase le consentyr en ella estar en lo que toca a la dicha villa, dexando aparte lo del dicho sennor rey.

E con tanto que se obliguen, el dicho Pero Ochoa e su muger, con su liçençia, por fuerte obligaçion, con juramento, quel dicho Pero Ochoa conplira lo susodicho e non tratara mal ni danno alguno nin deseruiçio del dicho sennor rey o en perjuisio de la dicha villa e jueses y ofiçiales della, de fecho nin derecho nin consejo nin publico nin escondido.

1477, Anónimo, Condiciones para vivir en la villa tras un destierro. Apud CORDE.

En estos dos ejemplos la ambigüedad procede del empleo de la locución conjuntiva oracional y, por tanto, de su valor condicional restrictivo, unido, por un lado, a la naturaleza del enunciado introducido, que es el último de una secuencia, y, por otro, a la interrupción de la estructura, dado que no aparece el correlativo verbo „principal“. En ambos casos, el empleo en un contexto de discurso referido podría hacernos resolver la confusión considerando que la conjunción copulativa está uniendo el que posterior a con tanto con el que introductor de la completiva de dixo en el primer ejemplo y en el segundo, de manera indirecta, con las decisiones del concejo - „consentyr en ella estar“ y „que se obliguen“; no obstante, en este segundo, podría interpretarse que se trata de una conjunción oracional condicional y que sólo posteriormente se pierde el hilo sintáctico. Seguramente estas 
confusiones estén favorecidas, como decía, por la naturaleza oral desde el punto de vista concepcional de estos textos.

También es cierto que el elemento principal de esta locución, el pronombre tanto - como sucede igualmente con todo, esto o eso - es recurrente en la formación de conectores: es el primer elemento de las consecutivas y el principal de los conectores extraoracionales consecutivos por lo tanto, por tanto, entre otros. Su carácter pronominal favorece su uso con valor deíctico y anafórico pues en él se recoge todo lo dicho con anterioridad, de ahí que también haya sido utilizado como conector interoracional temporal con sentido de ,posterioridad“ (Méndez García de Paredes 1995: 149). Ahora bien, no ha sucedido lo mismo en todas las épocas (Herrero Ruiz de Loizaga 2003: 362-63), ni tampoco con todos los posibles usos del pronombre pues hasta la actualidad han llegado las formas en tanto y entre tanto, ambas con sentido de tiempo intermedio ${ }^{5}$.

\section{Cronología de las apariciones de con tanto}

Para realizar este rastreo he utilizado la base documental del CORDE, por lo que no hay que perder de vista el carácter relativo de las cifras, sometidas a las características particulares del corpus. En el siglo XIII encontramos 21 ejemplos de este marcador en prosa. En el siglo siguiente el número de casos aumenta sólo de forma moderada: 35 , cifra que se mantiene aproximadamente en el XV y que, en cambio, se cuadruplica en el XVI con 127 ejemplos. En el XVII comienza de nuevo el descenso a 71 casos. En el XVIII desaparece y vuelve a aparecer un par de muestras en el XIX (uno en un texto científico y otro en uno de sociedad).

\section{Función de con tanto}

4.1. De los 21 ejemplos del siglo XIII, 7 están en textos de derecho, 3 en documentos historiográficos, 9 en obras relacionadas con el mester de clerecía, uno en un texto narrativo y otro en un texto didáctico, de literatura sapiencial concretamente. En el siglo siguiente, los casos se reparten entre textos de derecho (4), narrativos (3), didácticos (2), científicos (2), obras relacionadas con el mester de clerecía (3) y textos historiográficos (21). En el XV desaparecen los casos de los textos menores y se concentran en los de derecho (25) y los narrativos (6), mientras que en el XVI los que aumentan hasta 100 son los textos historiográficos. En el XVII disminuyen estos a $17 \mathrm{y}$, en cambio, incrementan los casos en los textos narrativos (33), con algunas muestras en los demás (6 en los didácticos, 3 en los científicos, etc.).

5 Con este valor se encuentra también en otras lenguas románicas como el italiano, cuya influencia durante los Siglos de Oro, con Bembo, Castiglione, Erasmo, etc., pudo suponer un elemento favorecedor del uso de nuestro con tanto. 


\begin{tabular}{|l|c|c|c|c|c|}
\hline CON TANTO & XIII & XIV & XV & XVI & XVII \\
\hline $\begin{array}{l}\text { Textos de derecho (ordenamientos y códigos } \\
\text { legales, tratados jurídicos, documentos } \\
\text { notariales, etc.) }\end{array}$ & 7 & 4 & 25 & 1 & 3 \\
\hline $\begin{array}{l}\text { Textos narrativos (relato extenso en novela, } \\
\text { relato breve, relato breve culto, relato extenso } \\
\text { en diálogo, etc.) }\end{array}$ & 1 & 3 & 6 & 11 & 33 \\
\hline $\begin{array}{l}\text { Textos didácticos (sapiencial, tratadística, } \\
\text { paremiología) }\end{array}$ & 1 & 2 & & 3 & 6 \\
\hline Textos científicos & & 2 & & 7 & 3 \\
\hline Textos sociológicos & & & & 5 & 3 \\
\hline Textos religiosos & 9 & 21 & & 100 & 17 \\
\hline $\begin{array}{l}\text { Textos historiográficos (cartas y relaciones, } \\
\text { memorias y diarios, historiografía, etc.) }\end{array}$ & 21 & 35 & 31 & 127 & 71 \\
\hline Otros & 3 & & & 3 \\
\hline Total & & & & & 3 \\
\hline
\end{tabular}

Figura 2.

En resumen, este marcador, heredado de los textos de derecho (siglos XIII, XIV y XV) pareció ,triunfar' para narrar en la historiografía, con ese extraordinario crecimiento durante el siglo XVI, y en el siglo XVII, cuando empezó su declive, para narrar en la ficción.

4.2. En cuanto a los usos y valores de con tanto, lo que se observa en un principio es que la anáfora que conlleva el pronombre indefinido es lo que le otorga la capacidad de introducir el final de una serie. Si bien en los primeros textos puede interpretarse más literalmente, a lo largo del transcurso de la historia va aumentando su grado de fijación y, por tanto, de gramaticalización.

4.2.1. Desde el segundo cuarto del siglo XIV pueden ya encontrarse ejemplos donde cabe interpretar que la locución funciona en el nivel textual y no como sintagma de significado literal, si bien en ninguno de esos casos puede asegurarse aún con rotundidad:

(3) Et si la seynnal ho el solariego quisiere leuar a los uillanos a las labores deuant dichas el sayon deue yr con eyllos \& el sayon non deue fazer ninguna labor. \& el sayon deue demandar ad aqueill seynor pora quien le faze labrar iantar o çena quoal que aya menester. Si los labradores quisieren pan de trigo deue sacar del Rouo de trigo .xvj. panes uno pora el sayon \& el otro pora aqueill qui lo cueze. daqueillos .xvj. panes. Et de los otros dar les sendos panes \& con tanto pasen. \& si quisieren abondo la meatat sea de ordio \& la otra meatat de trigo.

1300-1330 Anónimo, Fuero Navarra. Apud CORDE. 
La sucesión de enunciados que contienen cantidades numéricas puede haber propiciado la aparición de con tanto, pero coincide con el final de una secuencia narrativa. Estos dos hechos impiden que hablemos todavía de marcador discursivo pues suponen un contexto ambiguo.

4.2.2. En los ejemplos del siglo XV, con tanto puede presentar ya los siguientes valores. Unas veces introduce o marca el final de un texto o de una sección donde se reproduce una enunciación oral (cf. Cano Aguilar 1998, Eberenz 1998):

(4) [Es el epílogo de un libro, donde el autor alude de forma directa a su receptor, le da algunas instrucciones finales sobre el uso que puede darle a su obra y finalmente lo bendice.]

E asý como después del muy yllustre señor prínçipe don Carlos, a quien Dios prospera sobre todos los bivientes, vos seades mi syngular Señor, quiero comunicar con vos todo lo que es en mi ánima amagado, vos palpable mente non tangades con vuestro dedo, e con tanto resçebid estas primiçias del trabajo de mis manos, perdonado el error sy aý estoviere, alabando a Dios glorioso por algúnt bien sy ý fuere fallado, al qual ruego que en este mundo vos dé los bienes de la su graçia e virtud e en el otro la bien aventurança perdurable por syenpre. Amén.

Este libro es acabado, Nuestro Señor Dios sea por siempre loado. Amén.

c 1430-1440, Alfonso de la Torre, Visión deleytable. Apud CORDE.

(5) [Es el acta de un pleito puesto al propio tribunal de justicia, primero se ha presentado el caso, han declarado los testigos y llegamos al final donde el juez dicta sentencia. Después de fallar, solo viene la orden de que se cumpla lo que manda el juez y la enumeración de todos los testigos.]

E otrosi, fallamos que non deuemos facer condenacion de costas nin facemos [...]. E que los dichos vecinos se paren e paguen la costa de la yantar que oi, día de la pronunciacion, han fecho e receuimos con el dicho señor don Pero Velez. E con tanto los damos por ygualados e por asueltos la vna parte de la otra e la otra de la otra de todas las aciones e demandas a causa de que otorgaron el dicho poder e compromiso a nos, los dichos jueces.

1455, Anónimo, Sentencia de pleito [Documentación medieval de la cuadrilla de Salvatierra]. Apud CORDE.

En estos casos la locución cierra el acto de habla que se reproduce, de ahí que conserve en cierta medida el carácter deíctico propio del pronombre, e introduce los últimos actos de habla del texto. Curioso es el uso que se le da en este otro tipo de documento, donde parece haberse convertido en elemento integrante de una fórmula estereotipada, con la que se concluye la declaración de los intervinientes, pues se encuentra hasta 9 veces:

(6) [...] E luego, el dicho Pero Saes, dicho Perylo, puso demanda en juysyo antel dicho sennor alcalde a Pero Vrtys del Vdayaga tresyentos maravedis por puro prestydo que le obo dado; e que podya aver fasta quatro meses e asas de 
vezes se los avya pedydo e non se los avya quesydo dar; por ende, dyxo que su merçed le condenase e, en condenando, le mandase dar e pagar; e sy por el fuese negados, que lo jure ante su merçed o que lo enfrrasca. E (Página 770) inploro su ofyçio e pedyo segund de suso; e con tanto, dyxo que concluya e concluyo e pedya libramiento.

E luego, el dicho Pero Vrtyis dyxo que era verdad quel dicho Pero Saes, que presente estaba, le obo dados los trezyentos maravedis, pero que no los telnia al presente, pero el los querya dar a vn plaso, que su merçed del dicho alcalde mandase; e con tanto, non querya jurar nin resçibyr; e que concluya e concluyo e pedio sentençia e libramiento.

1498, Anónimo, Actos de jurisdicción e apeamiento [Colección documental del Archivo Histórico de Bilbao ]. Apud CORDE.

$\mathrm{Su}$ redundancia parece remitir a una estructura donde primero se plantea el caso sobre el cual se presta declaración y, después, se realiza - o no - el juramento.

Asimismo es posible encontrar con tanto para marcar el final de una enumeración o de una secuencia narrativa:

(7) é yo é los mios fuemos en los barcos de los castellanos, é nuestra nao tras nosotros, é entramos por el puerto de Constantinopla, é dexámosla, é fuemos á surgir á la paliçada de Pera, que es una de las mejores cosas del mundo; una nao, quan grande puede ser, tiene el esporgidura en tierra con tanto fondo é tan limpio, que mejor non puede ser; é deçendí en tierra bien acompañado de los castellanos é de otras naciones sus amigos dellos, é fuemos á la yglesia á fazer oraçion é allí fallé al Potestad que rige la tierra é me resçibió mucho bien, demandándome de las nuevas del Poniente é diziendo que toda cosa que oviese menester lo fallaría bien presto; é con tanto nos partimos. Yo me fuí aposentar con el patron castellano, donde fallé á osadas buen acogimiento, é como llegué á la posada, fallé un grant presente de vinos é aves [...].

c 1457, Pero Tafur, Andanças e viajes, Apud CORDE.

En esta obra de Pero Tafur hay seis ejemplos similares en total, puesto que su obra es una crónica de viajes. También en la de Lope García de Salazar encontramos varios ejemplos, si bien es más interesante observar en ellos la gramaticalización de la secuencia, dado que pierde todo valor déctico, adquiere un sentido distinto y, por otra parte, puede desplazarse en el enunciado en el que se inserta y encontrarse al principio (4), en medio (2) o al final (4), pero siempre coincidiendo con el final del capítulo, como se muestra en los ejemplos:

1471-1476, Lope García de Salazar, Istoria de las bienandanzas e fortunas. Apud CORDE.

(8) E, con tanto, se partieron los Reyes de Archiles.

Título de cómo los griegos eran acordados de se partir de Troya, sinon por el falso obispo Colcas, traidor

Ulixes e Diomedes e el duque Néstor (que) se fueron al rey Gamenón, [...] 
(9) E desapareçióle con tanto.

Título de cómo el Caballero del Çisne peleó con los sasones e de la muerte de Galieno $[\ldots]$

Pasado todo esto, el Caballero del Çisne pidió por merçed al Enperador que

(10) [El rey da un discurso a sus vasallos: primero el narrador le cede la palabra y luego él mismo termina de explicar lo que dijo el rey para enlazar con la narración.]

„[...] e porné mi real a las puertas de aquella villa de Algezira e estaré allí como cavallero fasta que la tomase o peligrase sobre ella."

E que las menguas qu'él en esto fiziese que no serían contadas a él, sino a los de sus reinos. E salióse con tanto del palaçio. E los del reino, que tales palabras le oyeron dezir, tornaron a su fabla e dixieron que debrían dar graçias a Dios porque les quiso dar tan noble rey e otorgáronle aquella alcavala de lo que se vendiese en sus reinos para durante la çerca de la dicha çiudad de Algezira con juramento de no la demandar más.

Título de cómo fue çercada la dicha çiudad de Algezira

Este noble Rey çercó la dicha çibdad en este año de mil CCCXLV años [...]

Lo mismo se encuentra en la Traducción de la historia del noble Vespasiano, donde también hay ejemplos con el marcador al principio (4) y en el medio (4).

Idéntica función puede desempeñar en ocasiones otra secuencia léxica similar, con esto, aunque en ella el demostrativo conserva más su valor deíctico que en el caso de con tanto y la secuencia significa por la suma de sus elementos. En consecuencia, respecto de con esto, no puede hablarse ni siquiera de cierto grado de gramaticalización:

(11) A las quales palabras el dicho Ochoa Sánchez le dixo así:

- Por çierto, Lope Garçía, [...].

E Lope Garçía le respondió e dixo así:

- Ya vos dixe, Ochoa Sánchez, e vos dezides bien e creed, que otra vez vos digo, que si en mi poder fuese e fuere, que no lo sería ni será, ca lo querría él por secutor, commo lo vieron mis anteçesores, pero no por juez e secutor, * que no ha menester más para ser señor soberano del dicho condado.

E con esto se partieron de en uno.

1471-1476, Lope García de Salazar, Istoria de las bienandanzas e fortunas. Apud CORDE.

4.2.3. En el siglo XVI los ejemplos continúan valores y usos del siglo anterior. Puede presentarse al final de una secuencia narrativa, para introducir el último enunciado, donde suele ir más frecuentemente al inicio, sin que falten casos con las otras posiciones:

(12) [Lo que precede es la explicación que se le da al rey sobre un asunto, cuyo contenido no nos interesa pero sí el preámbulo para formular la consulta.] 
venian en quitar la dicha clausula y poner otras palabras en lugar della de las quales no se satisfacieron los procuradores y ellos dieron otras que me consultaron de lo qual va la razon aparte y como yo vi esta diferençia y desseaua no concluyr este negocio por ser tan importante sin consulta de V. magestad determineme a respondelles que se lo queria consultar y que ellos se fuesen a sus çiudades y que venida la respuesta de v. mag.estad los mandaria llamar si conuiniesse y con tanto quedo el negocio suspenso.

1551, Anónimo, Cortes de Madrid. Apud CORDE.

Estos casos son mayoritarios y suelen conllevar el uso del pretérito indefinido (ochenta y tres, en total) - si bien hay también algunos con imperfecto (se han contado diez en el siglo XVI) y perfecto (uno solo) - y de verbos de movimiento ${ }^{6}$ como volverse (14 casos), partirse (7), irse (9), quedarse (8), salir(se) (7), embarcarse (3) y otros que implican indirectamente un movimiento, como es el caso de despe$\operatorname{dir}(s e)$ (7): como se ve, verbos que implican fin de una etapa, pues el movimiento da lugar a una nueva situación. Así pues, este significado último favorece y redunda en esta idea de final de secuencia, al mismo tiempo que es posible que esos términos hayan facilitado que se frenara el proceso de gramaticalización de con tanto, pues ya en ellos estaba contenido el principal valor del marcador: marcar el enunciado que introducía como el último de una secuencia. Además, las dos propiedades citadas, el pretérito indefinido y los verbos de movimiento, no sorprenden, ni mucho menos, en una narración; sin embargo, sí resultan caracterizadoras del contexto de aparición de este marcador en su empleo como organizador de la narración.

También puede aparecer para marcar el final de un texto o de una sección de un acto de habla como pueda ser una carta privada, concebida como conversación entre personas distanciadas (ejemplo 13), o un diálogo, sea en prosa, sea en una obra teatral (14):

(13) [Es una carta donde el remitente explica la crítica que ha tenido un libro suyo, especialmente desde Francia. Estamos al final de la carta.]

Y ansí, considerando vuestra persona y otras de vuestro grado y letras, digo que me maravillo de aquel dotorejo de Aristóteles que un libro que compuso De animalibus, que vos debéis tener metido en la cabeza, afirmó que en Francia no había asnos, siendo tan gran mentira, pues vemos que en París se hacen cada año tantos bachilleres.

Y con tanto, quedo deseando ver alguna obra vuestra, por emplear mi ingenio en defenderla y alabarla como vos habéis hecho á la mía, que siempre os lo agradecerá este vuestro buen amigo. - El Capitán Salazar.

c. 1550, Capitán Salazar, Respuesta de Capitán Salazar [Cartas del Bachiller de Arcadia al Capitán Salazar]. Apud CORDE.

6 Cito únicamente los verbos que presentan más de dos ejemplos para no caer en la casuística. 
(14) [Estos dos personajes, Pinciano y Palatino, están citándose.]

PINCIANO: Las obras lo dirán. Yo os esperaré hasta hora de queda, y si no llegárades a ella, pensaré que sois quedado y os habré por condenado en la sospecha y en la cena. Y con esto y con vuestra licencia, me parto.

PALATINO: Yo consiento en el término, con condición que no ande el reloj y la campana tan delantero como el de Simancas. La liebre esté bien aparejada y la mesa a punto. Y con tanto, os doy mi bendición y la de Dios, que vaya con vos.

PINCIANO: Él sea en vuestra guarda y os guarde de mala compañía. Amén.

Fin de la jornada nona.

1550, Juan de Arce de Otárola, Coloquios de Palatino y Pinciano. Apud Corde.

En el ejemplo 14, además, se puede ver el contraste entre la gramaticalización de con tanto en la intervención de Palatino y su ausencia en la primera de Pinciano en „con esto y con vuestra licencia“, donde la coordinación a otro sintagma muestra claramente que con esto se utiliza con su pleno valor deíctico y que, aunque también esté al servicio de la cohesión textual, no se trata de un marcador del discurso.

Relacionados con los ejemplos número 13 y 14, están los casos donde la reproducción de un acto de habla supone la existencia de varios planos, que separan la realidad de la ficción y, por tanto, el enunciado de la enunciación. Me refiero a los momentos en que el narrador introduce el estilo directo para que se „oiga“ la voz de sus personajes o cuando es su propia voz la que aparece, dirigiéndose al lector o aludiendo a su discurso de manera explícita.

Podemos observarlo en la Historia general y natural de las Indias de Gonzalo Fernández de Oviedo, donde al menos cinco capítulos se concluyen con este marcador. Además, lo relevante no es solo que se encuentre en ese contexto, sino que puede hacerlo también en secciones del texto donde aparece la voz del autor dirigiéndose directamente al lector:

(15) aquellas almendras del cacao que se dijo de suso, las cuales entre aquellas gentes corren por moneda e sirven de moneda, e por ellas se compran todas las cosas en aquella tierra, de los árboles de las cuales e de esa mesma fructa e de sus efectos, largamente se tractó en el libro VIII de la primera parte capítulo XXX, donde el letor lo hallará. E con tanto, se ha dado fin a las relaciones que el gobernador Hernando Cortés envió a César en diversos tiempos. Pasemos adelante con nuestra historia de la Nueva Espana.

1535-1557, Gonzalo Fernández de Oviedo, Historia general y natural de las Indias. Apud CORDE.

En estos casos, el marcador no va acompañado de los rasgos que mencionábamos anteriormente; de hecho, se ha atestiguado que pueden aparecer otros tiempos y otros modos: en futuro, por ejemplo, se han encontrado dos casos y ambos con función de organización del discurso explícita:

(16) Y con tanto le dexaremos en su cerco por contar lo que sucedió al hijo con Mulei Buazón. 
a. 1575, Diego de Torres, Relación del origen y suceso de los Xarifes y del estado de los reinos de Marruecos, Fez y Tarudante. Apud CORDE.

(17) E con tanto, diré ahora lo que sucedió en la ciudad del Cuzco.

c. 1553-a. 1584, Pedro Cieza de León, Las guerras civiles peruanas. Apud CORDE.

En presente de indicativo hay diecinueve ejemplos, donde se aprecian los dos extremos de la gramaticalización del conector: si el verbo es de movimiento de partida o de final, parece que con tanto recupera su valor léxico (18-20), pues el presente y la primera persona, si es ésta la que realiza la acción de concluir o de marcharse, impelen a la interpretación literal ${ }^{7}$; en cambio, si el verbo no alude de forma explícita a ningún tipo de movimiento sino a sus consecuencias indirectas, entonces el conector resulta más gramaticalizado (21-23), pues introduce un nuevo acto de habla:

(18) Y con tanto, entro.

(19) Y con tanto, salgo en nombre de Dios.

1554, Juan Rodríguez Florián, Comedia llamada Florinea, que tracta de los amores del buen duque Floriano con la linda y muy casta ... Apud CORDE.

(20) Y con tanto, pongo fin a las guayas. (,lamentaciones')

1570-1579, Sebastián de Horozco, Libro de los proverbios glosados. Apud CORDE.

(21) Y con tanto, veso las manos a Vuessas Mercedes.

1553, Antonio de Torquemada, Coloquios satíricos. Apud CORDE.

(22) y con tanto, es su fuerça en aparencia y de efecto sólo en un puesto.

1595, Bernardino de Mendoza, Teórica y práctica de guerra. Apud CORDE.

(23) Y con tanto, quedan canonizados aquellos huessos.

1554, Francisco López de Gómara, La primera parte de la Historia natural de las Indias. Apud CORDE.

Otros sentidos no son tan claros. En este ejemplo parece adquirir un significado temporal como ,entre tanto', ,mientras tanto', es decir, un sentido temporal que tampoco está lejos del pronombre tanto (Méndez García de Paredes 1995: 148150):

7 Puede verse en el ejemplo 7 ,e con tanto, nos partimos“: si lo leemos descontextualizado, puede entenderse como presente o como pretérito indefinido y tan solo en el segundo caso estaría sirviendo de marcador. 
(24) [Están hablando de un enfrentamiento al que Polites va después de haber hecho un trato, pero Fulminato ha accedido porque cree que no volverá, pues está seguro de que va a morir en él.]

POLYTES: A Dios quedes. Hasta la buelta.

FULMINATO: Siquiera buelvas como el trigo que passa en Asturias, que no sabe retorno. Pero, -o, hi de puta, y qué necio buen comedimiento el mío! Y aun él si lo acceptara, y qué neciamente lo hiziera él en pensar que yo hablava de veras; e yo mucho más en hazerlo, aunque lo mandaran siete Florianos. Aunque al fin, como tuve el sí fingido, si le viera que lo aceptava, tuviera el dissimulado. E con tanto, me subo arriba, que ya llevan el manjar.

1554, Juan Rodríguez Florián, Comedia llamada Florinea, que tracta de los amores del buen duque Floriano con la linda y muy casta ... Apud CORDE.

Y en este otro parece equivaler a los conectores consecutivos (Narbona Jiménez 1978: 87-90):

(25) [Lazarillo se ha convertido en atún, entre los que vive, y está hablando con el capitán de los atunes, a quien tiene que vengar para devolverle los favores que le ha hecho.]

Y díjele: „gran capitán, no es tan grande mi miedo como algunos lo hacen, que, como yo tenga contienda con hombres, vase la lengua a lo que piensa el corazón. Mas ya me parece que tardo en cumplir mi promesa, y en darte venganza de nuestro contrario; con tanto, con tu licencia, quiero volver a dar fin a mi hecho." „Tú la tienes," me dijo.

1555, Anónimo, Segunda parte del Lazarillo de Tormes. Apud CORDE.

\section{Conclusión}

Se ha intentado mostrar la especialización que sufría esta locución en su función extraoracional. Seguramente, las limitaciones textuales y discursivas que se advertían durante sus ,siglos de esplendor“, junto con la abundancia de usos del pronombre que contiene - consecutivos, temporales, etc. -, que podía llevar en ocasiones a equívoco, serían el motivo fundamental para, primero, frenar su proceso de gramaticalización y, luego, conseguir que acabara desapareciendo. Ahora bien, el poco tiempo que pervivió permite caracterizarlo como marcador no argumentativo y relativo a la macroestructura textual dentro de las tipologías discursivas narrativa y dialogal, a imitación de los textos notariales, siendo sobre todo interesante su capacidad para introducir nuevos actos de habla.

Sevilla, septiembre de 2008 


\section{Referencias bibliográficas}

Briz Gómez, Antonio (2000): „El análisis de un texto oral coloquial“, en: Antonio Briz Gómez y Grupo Val.Es.Co. (eds.), ¿Cómo se comenta un texto coloquial? Barcelona: Ariel (Ariel Practicum), 29-49.

Cano Aguilar, Rafael (1998): „Presencia de lo oral en lo escrito: transcripción de las declaraciones en documentos indianos del siglo XVI“", en: Oesterreicher / Stoll / Wesch (eds.), 219-242.

Cano Aguilar, Rafael (2003): „Función sintáctica, significación gramatical y valor léxico en la conexión supraoracional“, en: José Luis Girón Alconchel et al. (eds.), Estudios ofrecidos al profesor José Jesús de Bustos Tovar, 1 y 2. Madrid: Editorial Complutense, 297-314.

Casalmiglia Blancafort, Helena / Tusón Valls, Amparo (1999[2002]): Las cosas del decir. Manual de análisis del discurso. Barcelona: Ariel.

Company, Concepción (2003): „La gramaticalización en la historia del español“, Medievalia 35, 3-61.

Company, Concepción (2004a): „Gramaticalización por subjetivización como prescindibilidad de la sintaxis“, Nueva Revista de Filología Hispánica LII, 1, 1-27.

Company, Concepción (2004b): „GGramaticalización o desgramaticalizción? Reanálisis y subjetivización de verbos como marcadores discursivos en la historia del español", Revista de Filología Española 84, 29-66.

Detges, Ulrich (1998): „Echt die Wahrheit sagen. Überlegungen zur Grammatikalisierung von Adverbmarkern“, Philologie im Netz 4, 1-25.

Detges, Ulrich (2000): „Time and truth: the grammaticalization of resultatives and perfects within a theory of subjectification", Studies in Language 24, 345-77.

Eberenz, Rolf (1998): „La reproducción del discurso oral en las actas de la Inquisición“, en: Oesterreicher / Stoll / Wesch (eds.), 243-266.

Fernández Alcaide, Marta (2009): Cartas de particulares en Indias del siglo XVI. Edición y estudio discursivo. Madrid / Frankfurt: Iberoamericana / Vervuert.

Fernández Alcaide, Marta (en prensa): „,Con tanto, Dios Nuestro Señor os guarde. Estudio variacional de pragmática histórica“, en: Elena Méndez García de Paredes / Yolanda Congosto Martín (eds.), Variación lingüística y contacto de lenguas en el mundo hispánico. Coloquio in memoriam Manuel Alvar. Madrid / Frankfurt: Iberoamericana / Vervuert.

Fuentes Rodríguez, Catalina (1987): Enlaces extraoracionales. Sevilla: Alfar.

Fuentes Rodríguez, Catalina (1993): „Conclusivos y reformulativos“, Verba 20, 171-198.

Fuentes Rodríguez, Catalina (1998[1996]): La sintaxis de los relacionantes supraoracionales. Madrid: Arco Libros.

García Izquierdo, Isabel (1997): „El funcionamiento de los conectores ilativos y su papel en los encadenamientos discursivos“, en: Antonio Briz Gómez et al. (eds.), Sobre l'oral $i$ l'escrit. Quaderns de Filologia. Estudis Lingüistics. Valencia: Universidad de Valencia, II, $165-181$.

Girón Alconchel, José Luis (2004): „Gramaticalización y estado latente“, Dicenda 22, $71-88$.

Herrero Ruiz de Loizaga, F. Javier (2003): „Los conectores consecutivos por eso y por tanto en textos dialogados (1448-1528)“, en: Estudios ofrecidos al Profesor D. José Jesús de Bustos Tovar. Madrid: Editorial Complutense, 361-374.

Himmelmann, Nikolaus P. (2002): „Lexicalization and grammaticalization: opposite or orthogonal?“, en: Walter Bisang / Nikolaus P. Himmelmann / Bjorn Wiemer (eds.), 2004, What makes grammaticalization? A look from its fringes. Berlín / New York: Mouton de Gruyter, 21-42. 
López Serena, Araceli / Borreguero Zuloaga, Margarita (2009): „Los marcadores discursivos y la variación lengua hablada vs. lengua escrita“, en: Óscar Loureda et al. (eds.), $L a$ investigación sobre marcadores del discurso del español, hoy. Madrid: Arco / Libros.

Martín Zorraquino, María Antonia / Portolés Lázaro, José (1999): „Los marcadores del discurso“, en: Ignacio Bosque / Violeta Demonte (eds.): Gramática descriptiva de la lengua española. Madrid: Espasa-Calpe, 4051-4213.

Martínez Camino, Gonzalo (2006): „Cortesía y poder: la petición como gestión del vínculo interpersonal en una asignatura universitaria impartida a través de ordenador (Webct)“, Lingüistica en la red [http://www.linred.com/articulos_pdf/LR_articulo_09112006.pdf].

Méndez García de Paredes, Elena (1995): Las oraciones temporales en castellano medieval. Sevilla: Servicio de Publicaciones de la Universidad de Sevilla.

Narbona Jiménez, Antonio (1978): Las proposiciones consecutivas en español medieval. Granada: Universidad de Granada.

Oesterreicher, Wulf / Stoll, Eva / Wesch, Andreas (eds.): Competencia escrita, tradiciones discursivas y variedades lingüisticas. Aspectos del español europeo y americano en los siglos XVII y XVIII. Tübingen: Gunter Narr.

Otte, Enrique (1988): Cartas privadas de emigrantes a Indias, 1540-1616. Cáceres: Consejería de Cultura, Junta de Andalucía, Escuela de Estudios Hispano Americanos de Sevilla.

Pons Bordería, Salvador (1998): Conexión y conectores. Estudio de su relación en el registro informal de la lengua. Cuadernos de Filología, Anexo XXVII. Valencia: Universidad de Valencia.

Pons Rodríguez, Lola (2009): „Los marcadores discursivos en la historia del español“, en: Óscar Loureda et al. (eds.), La investigación sobre marcadores del discurso del español, hoy. Madrid: Arco / Libros.

Portolés, José (2001): Los marcadores del discurso. Barcelona: Ariel.

Portolés, José (2004): Pragmática para hispanistas. Madrid: Síntesis.

Real Academia Española: Banco de datos (CORDE) [en línea]. Corpus diacrónico del español. <http://www.rae.es>[febrero-noviembre 2007].

Torquemada, Antonio de (1552): Manual de escribientes. Madrid: Anejo XXI del Boletín de la Real Academia Española, 1970.

Watts, Richard J. (2003): Politeness. Cambridge: Cambridge University Press. 